\title{
Quantitative T1 mapping and the fibrotic index in normal healthy volunteers; relationship to aging and cardiac dimensions
}

\author{
Tomas G Neilan ${ }^{1,2^{*}}$, Eri Watanabe ${ }^{2}$, Otavio R Coelho-Filho ${ }^{2}$, Ravi Shah ${ }^{1,2}$, Yucheng Chen², Bobby Heydari ${ }^{2}$, \\ Ron Blankstein ${ }^{2}$, Raymond Kwong ${ }^{2}$, Michael Jerosch-Herold ${ }^{3}$
}

From 15th Annual SCMR Scientific Sessions

Orlando, FL, USA. 2-5 February 2012

\section{Summary}

We aimed to publish normal data for the fibrotic index in a group of healthy volunteers. In healthy volunteers, the fibrotic index has acceptable test characteristics, has a range from 0.23 to 0.33 , and is associated with age, LA volume and LV mass.

\section{Background}

Current cardiac magnetic resonance (CMR) techniques provide an accurate assessment of replacement myocardial fibrosis (MF), but are of limited value for the detection and quantification of diffuse MF. T1 mapping is a novel approach for quantification of the expansion of the extracellular matrix. However, there are little published data on the normal range of the FI and its variation with age and gender.

\section{Methods}

Twenty seven healthy volunteers underwent a standard CMR with administration of gadolinium (Gd). T1 measurements, extending to 30 minutes post-contrast, were performed with a segmented, breath-hold Look-Locker sequence in 3 short axis slices, using $100 \mathrm{~ms}$, and $50 \mathrm{~ms}$ for temporal resolution of one pre- and three post-contrast acquisitions, respectively. We tested the segmental, inter-slice, inter-, intra-, and test-retest characteristics of the fibrotic index, as well as the association with other cohort characteristics.

${ }^{1}$ Cardiology, Brigham and Women's Hospital/Massachusetts General Hospital, Boston, MA, USA

Full list of author information is available at the end of the article

\section{Results}

Healthy $(\mathrm{N}=27)$ volunteers were $52 \%$ female, ranged in age from 21 to 72 , had a BMI of $27 \pm 6 \mathrm{~kg} / \mathrm{m} 2$, an LVEDV of $127 \pm 28 \mathrm{ml}$, an LV mass index of $44 \pm 8 \mathrm{gms} /$ $\mathrm{m} 2$, a max LA volume index of $33 \pm 10 \mathrm{ml} / \mathrm{m} 2$, and an EF of $64 \pm 7 \%$. The FI averaged $0.28 \pm 0.03$ (range 0.23 to $0.33)$, and was associated with age $(\mathrm{r}=0.76, \mathrm{p}<0.001$, Figure 1), maximal LA volume index $(\mathrm{r}=0.67, \mathrm{p}<$ $0.001)$, and indexed LV mass $(\mathrm{r}=0.52, \mathrm{p}<0.01)$. The FI was similar in males and females $(0.27 \pm 0.03$ vs. 0.28 $\pm 0.03, p=0.12$ ), however, the female cohort tended to be older than males ( 54 years vs. 45 years, $\mathrm{p}=0.14$ ). There were no differences in the FI between segments in a slice or between slices. The intra-, inter-, and testretest characteristics of the FI were acceptable (difference $0.004,95 \%$ CI -0.006 to $0.015,4 \%$, Figure $2 \mathrm{~A}$; difference $0.01,95 \% \mathrm{CI}-0.01$ to $0.01,5 \%$, Figure $2 \mathrm{~B}$; difference $0.005,95 \% \mathrm{CI}-0.005$ to $0.005,2 \%$ ).

\section{Conclusion}

In healthy volunteers, the fibrotic index has acceptable test characteristics, has a range from 0.23 to 0.33 , and is associated with age, LA volume and LV mass.

\section{Funding}

Dr. Neilan is supported by an NIH T32 Training Grant (T32HL09430101A1).

Dr. Kwong receives salary support from a research grant from the National Institutes of Health (R01HL091157).

Dr. Jerosch-Herold is supported in part by a research grant from the National Institutes of Health (R01HL090634-01A1). 


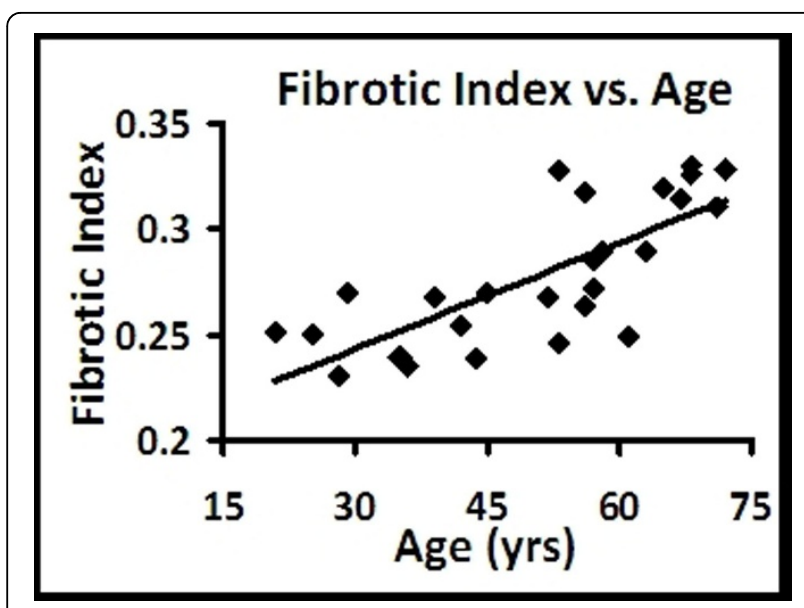

Figure 1
Author details

${ }^{1}$ Cardiology, Brigham and Women's Hospital/Massachusetts General Hospital, Boston, MA, USA. ${ }^{2}$ Cardiovascular Division, Brigham and Women's Hospital, Boston, MA, USA. ${ }^{3}$ Radiology, Brigham and Women's Hospital, Boston, MA, USA.

Published: 1 February 2012

doi:10.1186/1532-429X-14-S1-083

Cite this article as: Neilan et al:: Quantitative T1 mapping and the fibrotic index in normal healthy volunteers; relationship to aging and cardiac dimensions. Journal of Cardiovascular Magnetic Resonance 201214 (Suppl 1):083.

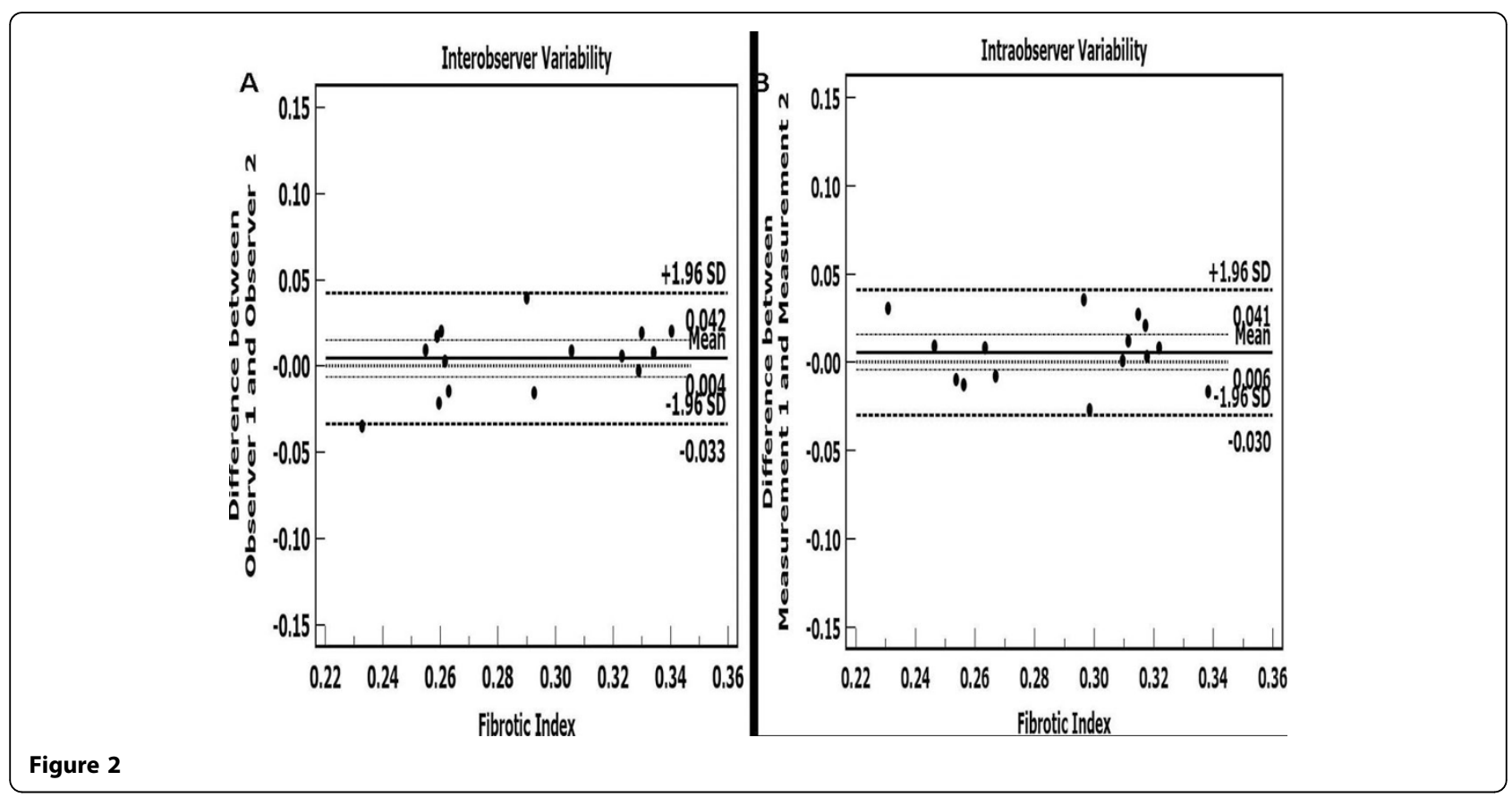

Submit your next manuscript to BioMed Central and take full advantage of:

- Convenient online submission

- Thorough peer review

- No space constraints or color figure charges

- Immediate publication on acceptance

- Inclusion in PubMed, CAS, Scopus and Google Scholar

- Research which is freely available for redistribution 